\title{
Skin in architecture: towards bioinspired facades
}

\author{
P. Gruber ${ }^{1,2,3}$ \& S. Gosztonyi ${ }^{4}$ \\ ${ }^{I}$ Transarch - Office for Biomimetics and Transdisciplinary Architecture, \\ Austria \\ ${ }^{2}$ Department for History in Architecture and Building Archaeology, \\ Vienna University of Technology, Austria \\ ${ }^{3}$ TU-Bionik Center of Excellence, Vienna University of Technology, \\ Austria \\ ${ }^{4}$ Austrian Institute of Technology, Austria
}

\begin{abstract}
In recent design programs and studies at the TU (Vienna University of Technology) the biological paradigm has been successfully introduced in architectural design. The focus of this paper is on the common analogy between biological skins and technical facades that was investigated in students' projects at the TU and is now developed further in the study BioSkin led by the AIT (Austrian Institute of Technology).

The facade of a building is responsible for energy and information exchange with the environment and defines the architectural character. The interpretation of facades in analogy to skins and bodyshells of organisms delivers a catalogue of functions that is only partly fulfilled by conventional facade technologies and allows for innovative, visionary concepts. Organisms have developed a wide range of strategies to cope with a changing external and internal environment: skins and body shells play an important role as separating and connecting structures required to protect, confine and contain processes of life from a chaotic environment.

A summary of existing projects and studies leading towards a biomimetic building facade is the base for further research aiming at energy efficiency and sustainability. Several design studies are presented that transfer aspects of natural skins to facade systems and materials, together with an introduction to research
\end{abstract}


that is focussed on models from nature for the architectural facade of the future within the frame of the BioSkin project.

Keywords: architecture, biomimetics, facade technology, energy efficiency.

\section{Introduction}

Beyond the layer of clothing as a "second skin", architecture is often referred to as a "third skin", delivering shelter and space for human activity. The biological paradigm has become more important than ever in the current architectural discourse. Issues of non-Euclidian form, environmental control, adaptation, smartness and intelligence, together with the development of new technologies, deliver new research fields. However, the biological model skin is usually only superficially investigated. A functional comparison is established as a basis for biomimetic transfer to provide deeper insight and prospects for further research.

\section{Functional comparison between the skin of organisms and building envelopes}

The function of skin and other outer hulls in nature bears many analogies to the function of facades in architecture. Skins, shells, cuticles, membranes and other outer layers of organisms protect, confine and contain living organisms. Architecture delivers an internal environment for mostly human activity, and facades create a difference between the inside and the outside.

The primary analogy between skins and building envelopes is the task of creation of a difference: the establishment of an internal environment. Difference concerns the composition of chemical substances and phases, and physical environment, for example a difference in movement of substances or radiation.

If organisms are concerned, the grade of difference needed relates to the environmental conditions on one side, and to the metabolism and energy and resource balance on the other side. The grade of difference needed in architecture also relates to the grade of comfort for the inhabitant. Yeang [1] suggested a differentiation in comfort ranges according to building functions and user requirements that define the grade of deviation between the internal external environments. In contrast to the beginnings of the climate control of buildings, technology is no longer restricted to the role of fine-tuning at the end of the design process, but is an integrated element in a bioclimatic approach.

Interaction between inside and outside takes many forms between total closure and total openness to matter and energy flows. Protection from mechanical influences, radiation, unwanted substances and other organisms is one of the most important functional aspects linking skin and building facades. But the border between inside and outside also has to provide mechanisms for exchanging matter and energy needed to maintain metabolism - permeability of some kind to air, water and nutrients is a precondition for life, and for providing an internal environment with today's comfort standards. 
Table 1: Functions of the skins of organisms and analogies in architecture.

\section{Create difference from environment, create internal environment}

\section{Skin function in organisms by/what}

architectural

analogy

Primary function, happens in the intermediate space between the inside and the outside

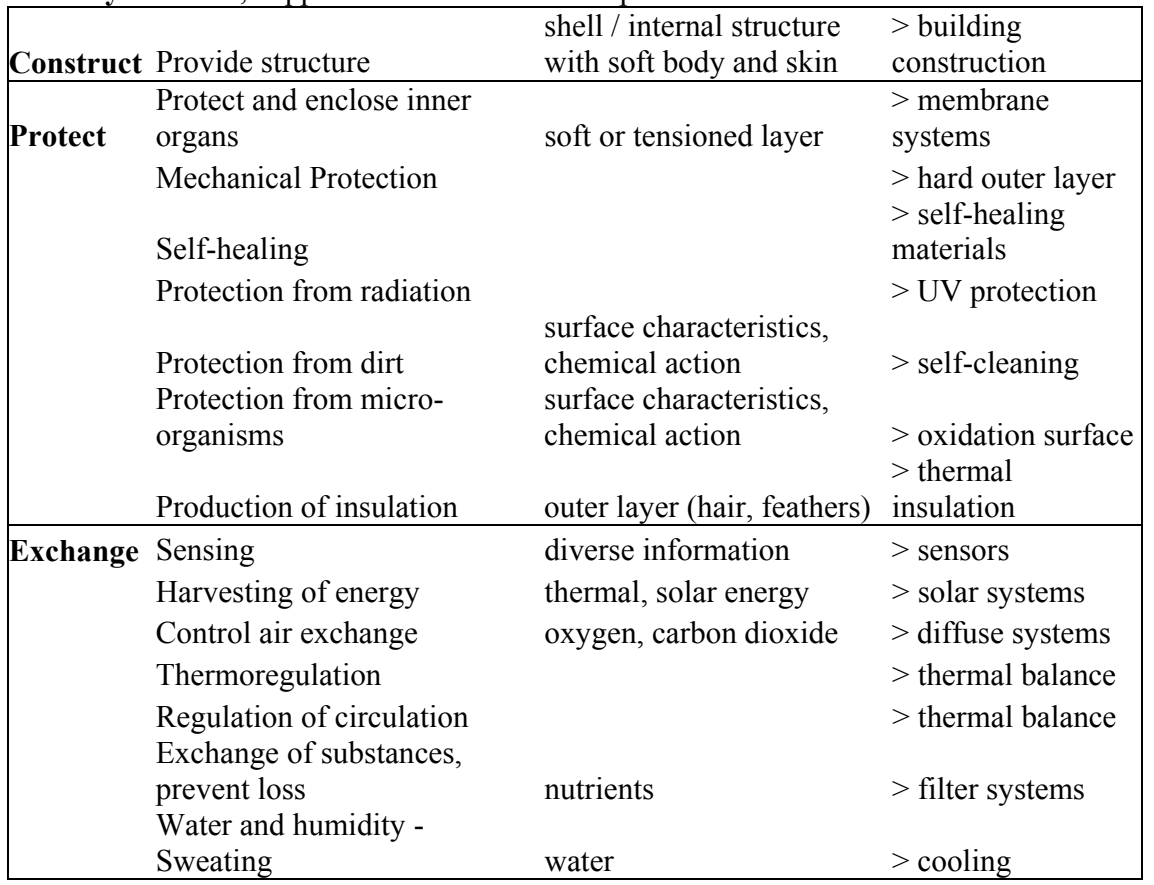

Integrated function, also use of a mechanism already there

\begin{tabular}{|llll|}
\hline Signal & $\begin{array}{l}\text { Appearance in environment } \\
\text { Signalling }\end{array}$ & $\begin{array}{l}\text { colour, patterns } \\
\text { colour change etc. }\end{array}$ & $>$ communication \\
\hline
\end{tabular}

Integrated function in the intermediate space, can also happen elsewhere in the organism

\begin{tabular}{|llll|}
\hline Store & Storage of energy & thermal energy & $>$ heat storage \\
& $\begin{array}{l}\text { Storage of chemical energy } \\
\text { ftorage of humidity }\end{array}$ & fat, sugar & $>$ energy storage \\
& & $>$ water storage \\
\hline
\end{tabular}

For architects flexibility is one of the most interesting features of biological skin. The range of forms and geometries of biological organisms is an ever inspiring source for the design of objects and buildings, and the vision of a flexible yet strong skin is appealing: current facade technology still struggles with the technical execution of double-curved forms that we are now able to design and control in theory. The aspect of change and transformation on the timescale of the individual building is also still unusual, and an issue of experimental designs. Communication and cohabitation aspects in nature can deliver new architectural solutions, especially for densely populated urban areas. 
Table 2: $\quad$ Important aspects of biological skin and analogy in architecture.

\begin{tabular}{|c|c|c|}
\hline \multicolumn{2}{|l|}{ Aspect of biological skin } & architectural analogy \\
\hline \multicolumn{3}{|l|}{ Transformation properties, time related } \\
\hline $\begin{array}{l}\text { Adaptability for environmental and } \\
\text { internal changes }\end{array}$ & & $>$ all aspects \\
\hline Structural provision for growth & $\begin{array}{l}\text { flexibility or shedding } \\
\text { of skin/shell }\end{array}$ & $\begin{array}{l}>\text { growth, form change } \\
>\text { form change, }\end{array}$ \\
\hline Structural provision for locomotion & flexibility or joints & locomotion \\
\hline \multicolumn{3}{|c|}{ Communication and cohabitation properties } \\
\hline $\begin{array}{l}\text { Tactile aspects } \\
\text { Provision of environment for other } \\
\text { organisms }\end{array}$ & symbiosis & $\begin{array}{l}\text { > visual aspects, } \\
\text { metaphor } \\
>\text { added value - urban } \\
\text { scale }\end{array}$ \\
\hline \multicolumn{3}{|l|}{ Multifunctionality and Integration } \\
\hline Layered but connected systems & & $>$ layers \\
\hline $\begin{array}{l}\text { Dispersed integration } \\
\text { Distinct integration }\end{array}$ & $\begin{array}{l}\text { sensors, blood vessels, } \\
\text { ventilation pores etc. } \\
\text { organs, nails, etc. }\end{array}$ & $\begin{array}{l}>\text { integrated function } \\
>\text { integration of } \\
\text { subsystem }\end{array}$ \\
\hline
\end{tabular}

Considering the already existing functionalities of clothes and buildings, we can state that human exchange with the natural environment is transferred to a specific distance from skin, whereas the supply of needed substances and potentials (water, nutrients, electricity, and information) is transferred closer, to a comfortable distance. The transfer of activation from skin and body to clothing and further on to building envelope makes the initial function of human skin as an interface between inside and outside unimportant.

As a consequence, dependence on technical systems increases, and there is less effort needed for the individual to keep up difference to the environmental conditions, but increased effort to generate difference between internal and external environment by means of technology. The integration of humans in a hull brings with it the necessity to create visual links between the interior and exterior and to provide sufficient illumination for human activities, new functions that find analogies in nature in systems where light is needed for sensing and generation of energy. Other functions coming from facade technology such as fire safety serve as starting points for a strategic search in nature, also going beyond the initial skin - facade analogy.

Visions of a living house take over activities that have been fulfilled by humans to maintain the internal environment. The "intelligent" or "smart" house cares for the comfort and support of the inhabitant. The integration of what is known as biological "signs of life" in architecture and building was investigated by Gruber [2] on many levels of scale, and it seems to be increasing, especially in the forefront of current architectural discourse. In spite of these efforts, poetic fantasies of living houses as proposed for example by Vian [3] still remain 


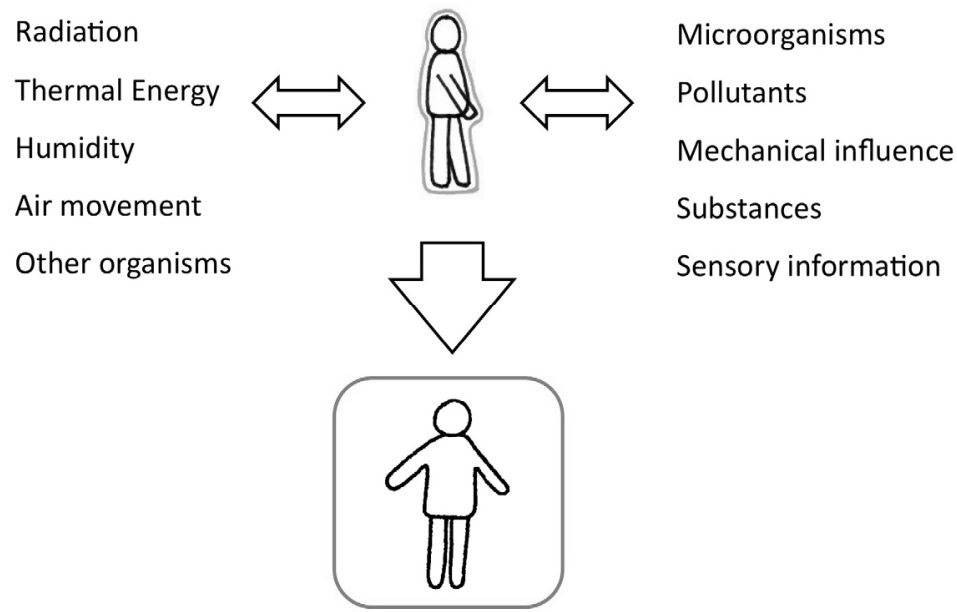

Figure 1: Exchange between the internal and external environment, transfer of the exchange layer away from the human body with clothes as the second, and buildings as the third skin.

science fiction: "The broken windowpane was starting to grow back, a thin film was forming on the side of the frame, with opalescent and iridescent splinters of an uncertain nature, of colours vague and changing..." [3]

\section{Skin as a active negotiator between inside and outside}

In vernacular building traditions houses usually do not contain active elements. Quality is achieved by the effective structuring of material that is available on a local basis, and adaptation to a local environment increased with experience in small steps, delivering "evolved" building typologies.

The activated building of today that continuously transforms resources, energy and information is a result of growing technological abilities and a wish for comfort.

A famous step towards a multifunctional facade was taken by Mike Davies in 1978 with the development of the concept of the "polyvalent wall" during the design of Rogers Lloyd's building in London. It was meant to integrate classic functions of sealing and insulation as well as environmental control, ventilation and individual control of lightning. A layered system fulfilled single functions. Today's facade technology still goes into the direction of separation of functions into layers and their incorporation within various building components, which are then ultimately combined in a modular facade [4].

The issue of separating internal from a potentially hazardous external environment is brought to the extreme in design for applications in outer space, where extreme temperature differences, radiation, solar particle events, meteoroids, and the mission phase itself provide unequalled problems. Research 
on an inflatable space station has been carried out since the 1960s, and resulted in the development of the TRANSHAB skin in 1998. The layered structure consisted of different carbon fibre products to provide protection and sealing. Further discussion of skins for extreme environments was carried out by Mohanty and Fairburn [5].

Technology driven innovations in facades technology are usually based on increased matter and energy transfer, so technologies for solar energy harvesting are increasing. Double facades, air volume with potential natural ventilation and adaptive sunshade are already standard means to control in and output of energy and daylight. Better energy management seems to be possible with the implementation of phase change materials that can store energy for delayed release. Communication and interaction has become common in facade design many architectural projects have integrated light systems and screens in facades to visualise information or environmental conditions. Ito's Tower of Winds 1986 in Yokohama was a famous precursor of this development that benefits from LED technology.

Biomimetics is increasingly used as innovation method for novel solutions in facade technology, with approaches targeted to structure and energy efficiency. Braun [6] investigated a range of biological models for specific functional requirements in facade design and assigned them to specific layers in a schematic outline of an adaptive permeable skin structure. Badarnah and Knaack [7] investigate organisational features in leaves for application in shading systems. Matini [8] investigated systems of flexibility and developed abstract geometric concepts that could deliver solutions for deployable structures and adaptable facades, a topic that is further investigated by Lienhard et al. [9].

Research on the scale of materials is carried out by many research groups, concepts ranging from research of moist air transport through natural materials to the development of self-healing membranes [10].

\section{Studies and prototypes}

The selected studies in biomimetics that were carried out under the supervision of the author at the Vienna University of Technology illustrate some of the functional transfers that can be carried out. A solution based approach was used the students could choose a phenomenon from nature to analyse and transfer to an architectural solution. In many cases the investigations of the students delivered a reasonable summary of the research that had been carried out on the respective phenomenon, and in about $25 \%$ of the exercise led to a reasonable design proposal [11].

The interest of many of the architecture students focused on morphological phenomena that delivered spatial solutions. Snake skin and different kinds of shells allowing form change were popular topics.

Thermoregulation, protection from heat loss was another important issue. Insulation in nature was investigated in many respects: furs and feathers were investigated and applied as adaptive insulation that relied on change of insulating air volume. One of the most successful designs took the old man cactus as role 

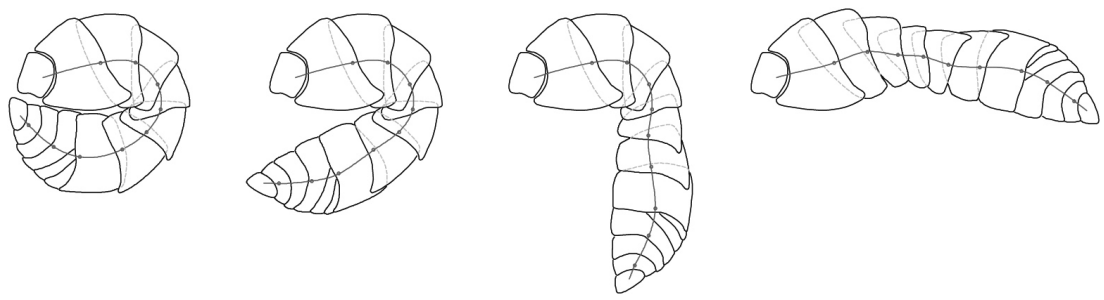

Figure 2: Drawings of shell segments: straight and curled up state [12].
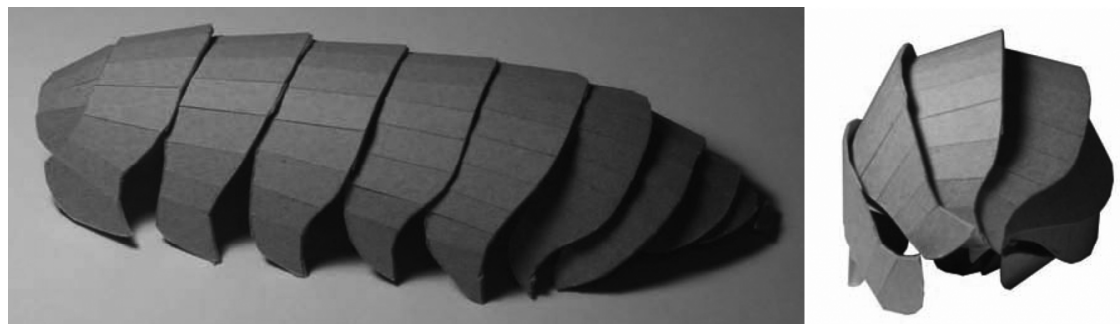

Figure 3: $\quad$ Pillbug shell: paper model [12].
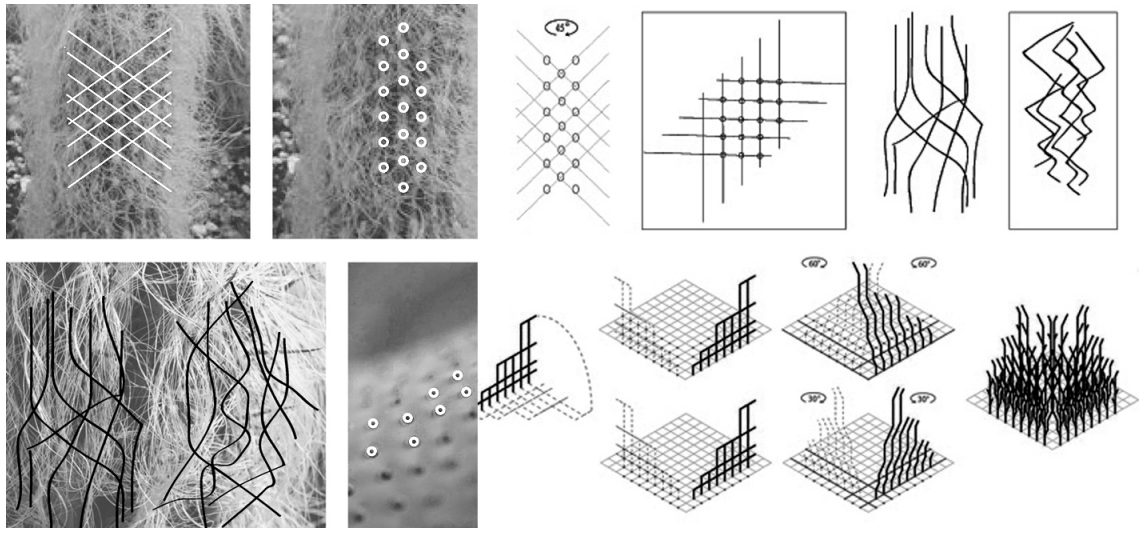

Figure 4: Hair pattern of old man cactus, translated into an abstract pattern for a sunshade system [14].

model: the natural pattern of the long white hairs of the cactus provides sunshade and an internal microclimate. The pattern formation was used and scaled up to be used for shading building facades [13].

Another design project, the roll-on habitat, interpreted the skin of elephants and the cats tongue in a super adhesive outside layer of a rolling habitat on the lunar surface, providing shelter from radiation in space with a layer of regolith moon dust [13]. 


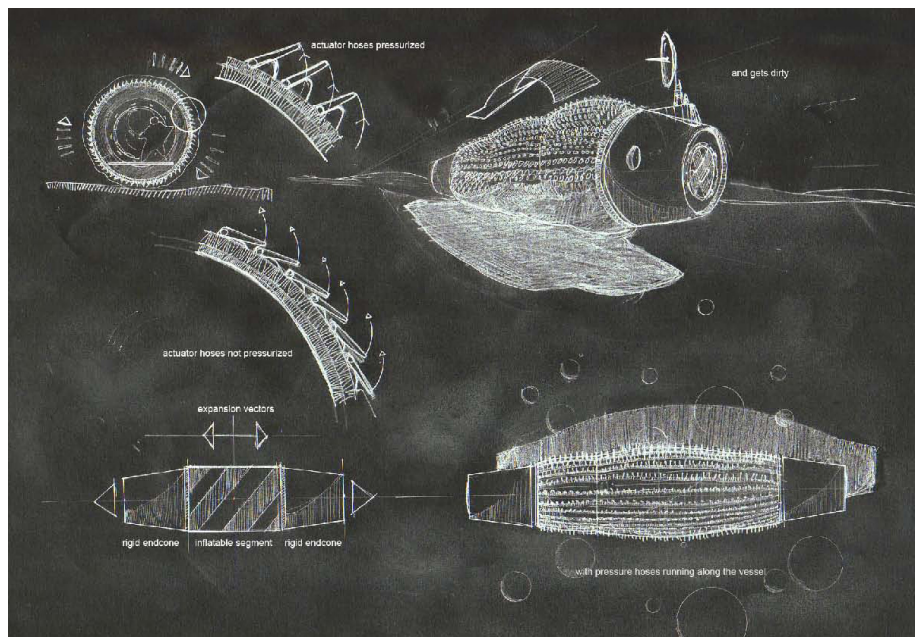

Figure 5: Rolling habitat for planetary exploration with a super adhesive surface to generate radiation shielding [15].
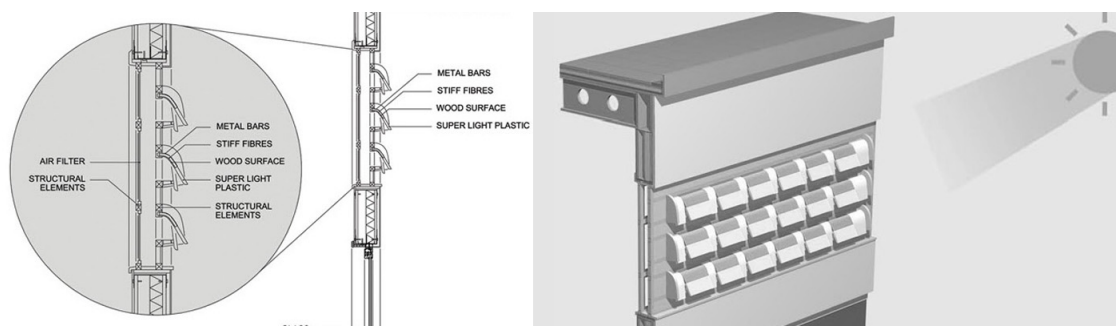

Figure 6: Ventilation openings using a pine cone mechanism [16].

Concepts for exchange concern mostly opening and closure systems for ventilation on material and structure level, inspired for example by the stomata of leaf surfaces or the passive opening mechanism of pine cones.

Signalling mechanisms from nature were another popular issue to investigate. A project inspired by cephalopod skin translated signalling as well as change of thermal properties $[17,18]$.

Exchange and storage of water was integrated in the project inspired by water storage cells of Lithops. Water evaporates through a semi permeable membrane, delivering change of transparency, control of solar input and humidity [19, 20].

A multifunctional approach was elaborated in a workshop project development that focused on the specific task of designing facade claddings. Considering the strong link between structure and function in biological systems, the discussion about facades without interpreting them as structural elements for the whole building seems strange, but proves useful in order to concentrate efforts on issues of exchange with the environment. The project was inspired by functionalities found in trees and barks of trees. 
The biomimetic approach used in the design exercises and programs is taken further in the BioSkin project, aiming at the development of novel energy efficient facades of the future (Project lead Austrian Institute of Technology). Functional analogies from nature based on questions arising in current facade
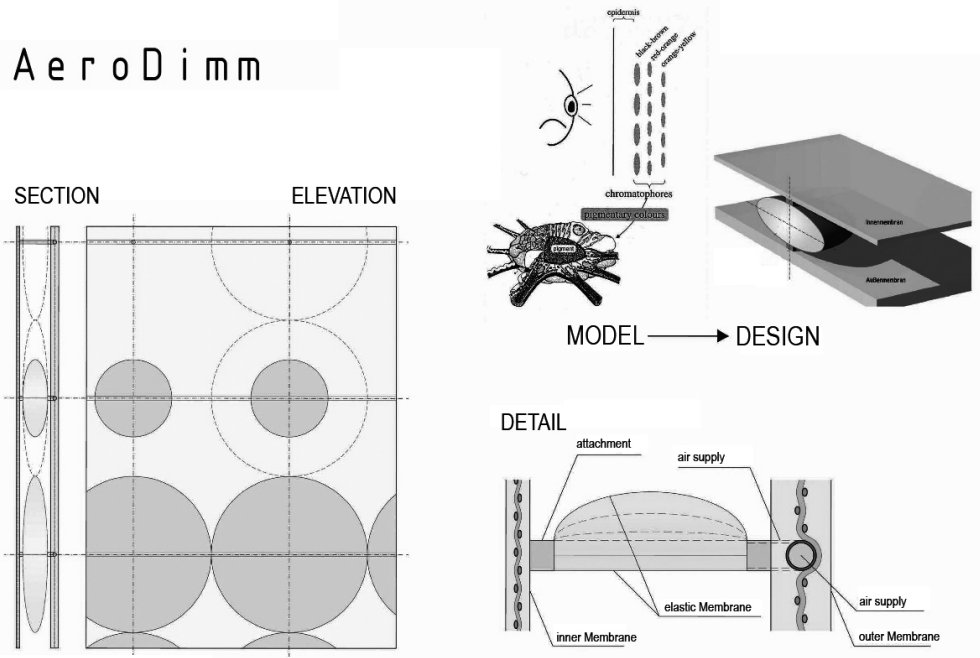

Figure 7: Concept for a pneumatic facade darkening inspired by cephalopods [17].

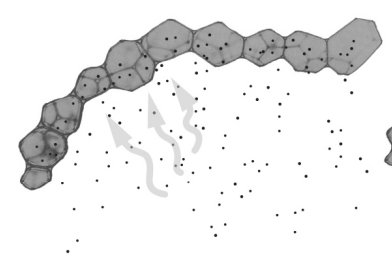

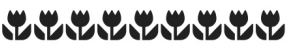
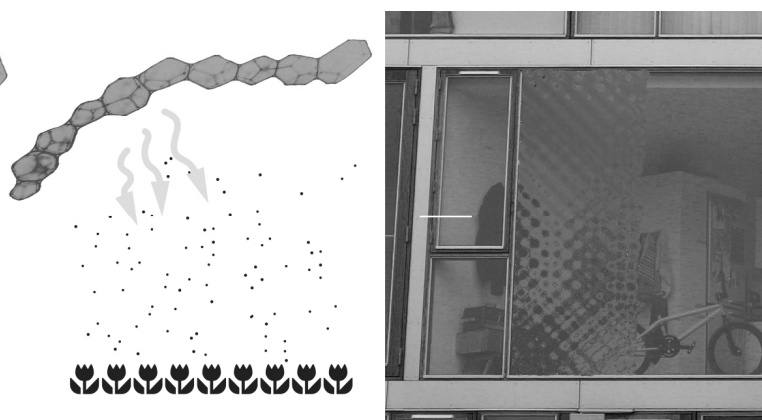

Figure 8: Facade system inspired by the water storage cells of Lithops [19].
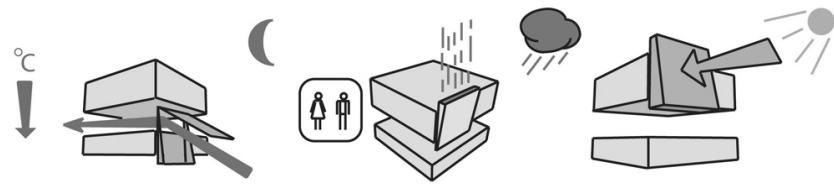

Figure 9: Functional schemes of the multifunctional facade: night cooling, water harvesting and solar energy harvesting [21]. 

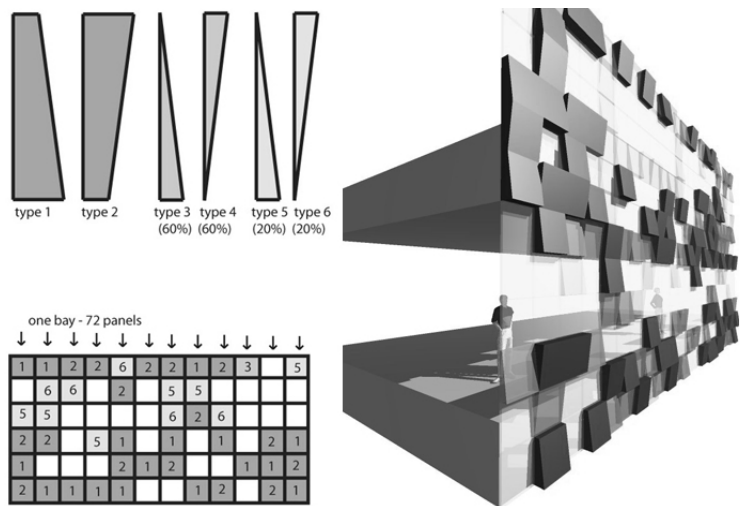

Figure 10: Modular tiling: pattern according to the required functionality [21].

technology are investigated. Groups of questions concern daylight transmission, thermal insulation, ventilation, cooling and energy. A first scan in biological databases delivered around 200 phenomena from nature that had interesting properties. Models with transferable characteristics will be identified in the next steps of the project, in order to identify underlying principles for concept development that will follow in 2010.

BioSkin is financed in the "Haus der Zukunft Plus" program by the Austrian Research Promotion Agency FFG.

\section{References}

[1] Yeang, K., The Green Skykscraper, The Basis for Designing Sustainable Intensive Buildings, Prestel Verlag, Munich, London, New York, 1999.

[2] Gruber, P., Biomimetics in Architecture [Architekturbionik] - Architecture of Life and Buildings, Doctoral thesis, Vienna University of Technology, 2008.

[3] Vian B., Foam of the Daze, first ed. 1963, TamTam books, 2003

[4] Knaack U. et al., Fassaden: Prinzipien der Konstruktion, Birkhäuser Verlag, 2007

[5] Mohanty S., Fairburn S., Skins by Design, Humans to habitat, 32nd International Conference on Environmental Systems, Vancouver, Canada, 2003.

[6] Braun, D.H., Bionisch inspirierte Gebäudehillen, Doctoral thesis, Institut für Baukonstruktion und Entwerfen Lehrstuhl 2, University Stuttgart, 2008.

[7] Badarnah L., Knaack U., Organizational features in leaves for application in shading systems for building envelopes, Design and Nature IV, Comparing Design in Nature with Science and Engineering, Brebbia, C.A. (ed.), WIT press, pp.87-96, 2007.

[8] Matini, M.R., Biegsame Konstruktionen in der Architektur auf der Basis bionischer Prinzipien, Doctoral thesis, Institut für Tragkonstruktionen und Konstruktives Entwerfen (ITKE), University of Stuttgart, 2007. 
[9] Lienhard J. et al., Abstraction of plant movements for deployable structures in architecture, Proc. of 6th Plant Biomechanics Conference - Cayenne November 16th-21st, 2009, pp. 389-397, 2009.

[10] Brebbia C.A. (ed.), Design and Nature III, Comparing Design in Nature with Science and Engineering, WIT press, 2006.

[11] Gruber P., Transfer of nature to architecture - analysis of case studies, Proceedings BAEC Biological approaches to engineering, Inst. Sound Vibr. Res., Southampton, UK, pp. 58-61, 2008.

[12] Fuchs K., Pillbug shell, Biomimetics Design Exercise, TU Vienna, 2005.

[13] Gruber P., Ideas for Space - Bioinspired Architectural Design, Bionik: Patente aus der Natur, Kesel A., Zehren D. (eds.) Bionik-InnovationsCentrum Bremen, pp.108-119, 2009.

[14] Trpenoski K., Cactus facade, Biomimetics Design Exercise, TU Vienna, 2007/08.

[15] Özdemir K., Roll on Habitat, Biomimetics Design Exercise, TU Vienna, $2007 / 08$.

[16] Sencer I., Pine cone facade, Biomimetics Design Exercise, TU Vienna, 2007.

[17] Pfaffstaller S., Aero Dimm, Biomimetics Design Exercise, TU Vienna, 2004.

[18] Gruber P., The Signs of Life in Architecture, Bioinspiration and Biomimetics, IOP Publishing 3/2007

[19] Steiner C., Lithops facades, Biomimetics Design Exercise, TU Vienna, 2008.

[20] Gruber P., Biomimetics in architecture - inspiration from plants, Proc. of 6th Plant Biomechanics Conference - Cayenne November 16th - 21st, 2009, pp. 412-419, 2009.

[21] Prodinger C., Prusa L., Tree facade, Surfcornwall Design Program TU Vienna 2007 